\section{Christine Ren Fielding}

\section{Christine Ren Fielding ${ }^{1}$}

Published online: 12 July 2019

(C) Springer Science+Business Media, LLC, part of Springer Nature 2019

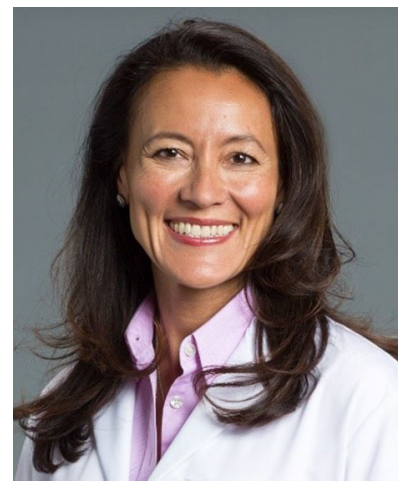

Christine Ren-Fielding, MD FACS FASMBS, Professor of Surgery at NYU School of Medicine, is the Chief of the Division of Bariatric Surgery and the Director of the NYU Langone Weight Management Program, which she founded in 2000.

Dr. Ren-Fielding obtained her medical degree at Tufts University School of Medicine in Boston, MA, followed by a residency in general surgery at NYU Medical Center. Dr. Ren-Fielding went on to complete a fellowship in advanced laparoscopic surgery at Mount Sinai Medical Center.

Dr. Ren-Fielding is recognized nationally and internationally for her contributions to the field of bariatric surgery. While performing over 4000 bariatric surgeries, she devotes much of her time to research, having been published in 230 peer-reviewed journals including the Journal of the American College of Surgeons and Annals of Surgery. She also serves on the Editorial Boards of Obesity Surgery, Surgical Obesity and Related Diseases, and Surgical Endoscopy.

Dr. Ren-Fielding has been an active committee member of the American Society for Metabolic and Bariatric Surgery for over 15 years, serving as Chair of the Insurance Committee, Chair of the Membership Committe and Member-at-Large on the Executive Council for two terms. As the ASMBS Chair of Insurance Committee, Dr. Ren-Fielding was instrumental in spearheading the creation of eleven new CPT codes for bariatric surgery. This has enabled insurance companies to cover these operations, which previously denied millions of Americans insurance coverage for these life-saving operations.

Dr. Ren-Fielding is the recipient of a 2004 YWCA Woman's Achievement Award, has appeared on "Oprah," was profiled in Crain's 2005 special issue on New York's Rising Stars, and has been a Castle Connolly Top Doctor since 2005.

Dr. Ren-Fielding is a native New Yorker, first-generation American of Polish and Chinese descent, and the oldest daughter of Sam and Lucy Ren. She lives in Manhattan with her husband, Dr. George Fielding, who is also a leader in bariatric and advanced minimally invasive surgery, and her black lab, Ebby. She is an avid enthusiast of fly fishing, duck hunting, gardening, and raising chickens.

Publisher's Note Springer Nature remains neutral with regard to jurisdictional claims in published maps and institutional affiliations.
Christine Ren Fielding

christine.ren-fielding@nyulangone.org;

christine.fielding@nyumc.org

1 School of Medicine, NYU Medical Center, New York, NY 10016, USA 